DOSSIÊ TEMÁTICO: Educação Inclusiva e Processos de Subjetivação

do/ https://doi.org/10.22481/praxisedu.v16i37.5982

\title{
PEDAGOGIA VISUAL NA EDUCAÇÃO DE SURDOS: UMA EXPERIÊNCIA COM O ENSINO DA MATEMÁTICA NO MATHLIBRAS
}

\author{
VISUAL PEDAGOGY IN DEAF EDUCATION: AN EXPERIENCE WITH MATH \\ TEACHING IN MATHLIBRAS
}

\section{LA PEDAGOGÍA VISUAL EN LA EDUCACIÓN PARA SORDOS: UNA EXPERIENCIA CON LA ENSEÑANZA DE LAS MATEMÁTICAS EN MATHLIBRAS}

\author{
Thaís Philipsen Grützmann \\ Universidade Federal de Pelotas - Brasil \\ Rozane da Silveira Alves \\ Universidade Federal de Pelotas - Brasil \\ Tatiana Bolivar Lebedeff \\ Universidade Federal de Pelotas - Brasil
}

\begin{abstract}
Resumo: O trabalho tem como objetivo apresentar e analisar dois vídeos produzidos no projeto de pesquisa "Produção de Vídeos de Matemática Básica com tradução em Libras - MathLibras", sobre o conteúdo frações. O projeto teve financiamento do Conselho Nacional de Desenvolvimento Científico e Tecnológico (CNPq) e é desenvolvido na Universidade Federal de Pelotas (UFPel), no Rio Grande do Sul (RS). Os vídeos produzidos no MathLibrassão considerados como um recurso visual para os estudantes surdos, entendendo suas singularidades de apreensão e construção de sentidos, fundamentados na Pedagogia Visual. No total o projeto já disponibilizou 13 vídeos no Canal do MathLibras no YouTube. O aporte teórico-metodológico está baseado nas obras de Campello (2007; 2008), Lacerda, Santos e Caetano (2014), Lebedeff (2010; 2017), Nogueira (2013), Nunes et al (2013), Silva (2010) e Smole e Diniz (2016).A tecnologia de produção de audiovisuais deu condições para que os vídeos do MathLibras propiciem, acredita-se, o protagonismo da Libras como língua de instrução, na perspectiva da Pedagogia Visual e Textualidade Diferida. É importante ressaltar, ainda, a importância do trabalho em uma equipe multidisciplinar e da comunicação contínua entre os diferentes grupos que constituem o projeto.
\end{abstract}

Palavras chave: Educação de Surdos; Matemática; Pedagogia Visual.

Abstract: The paper aims to present and analyze two videos produced in the research project "Production of Basic Math Videos with translation in Libras -MathLibras", about the content fractions. The project was funded by the National Council for Scientific and Technological Development (CNPq) 
and is developed at the Federal University of Pelotas (UFPel), Rio Grande do Sul (RS). The videos produced at MathLibras are considered as a visual resource for deaf students, understanding its singularities of apprehension and construction of meanings, based on Visual Pedagogy. In total the project has already made 13 videos available on the MathLibras YouTube Channel. The theoretical and methodological support is based on the works of Campello (2007; 2008), Lacerda, Santos and Caetano (2014), Lebedeff (2010; 2017), Nogueira (2013), Nuneset al (2013), Silva (2010) and Smole and Diniz (2016).Audiovisual production technology has enabled the MathLibras videos to provide, it is believed, Libras' leading role as a language of instruction, from the perspective of Visual Pedagogy and Deferred Textuality. It is also important to emphasize the importance of working in a multidisciplinary team and of continuous communication between the different groups that make up the project.

Keywords: Deaf Education; Mathematics; Visual Pedagogy.

Resumen: El artículo tiene como objetivo presentar y analizar dos videos producidos en el proyecto de investigación "Producción de videos matemáticos básicos con traducción en Libras - MathLibras", sobre las fracciones de contenido. El proyecto fue financiado por el Consejo Nacional para el Desarrollo Científico y Tecnológico (CNPq) y se desarrolla en la Universidad Federal de Pelotas (UFPel), Rio Grande do Sul (RS). Los videos producidos en MathLibras se consideran un recurso visual para estudiantes sordos. Sus singularidades de aprehensión y construcción de significados, basadas en la Pedagogía Visual. En total, el proyecto ya ha puesto a disposición 13 videos en el canal de YouTube MathLibras. El apoyo teórico y metodológico se basa en los trabajos de Campello (2007; 2008), Lacerda, Santos y Caetano (2014), Lebedeff (2010; 2017), Nogueira (2013), Nunes et al (2013), Silva (2010) y Smole y Diniz (2016).La tecnología de producción audiovisual ha permitido que los videos de MathLibras proporcionen, según se cree, el papel principal de Libras como lenguaje de instrucción, desde la perspectiva de la pedagogía visual y la textualidad diferida. También es importante enfatizar la importancia de trabajar en un equipo multidisciplinario y de una comunicación continua entre los diferentes grupos que conforman el proyecto.

Palabras clave: Educación para sordos; Matemáticas; Pedagogía Visual.

\section{Introdução}

O trabalho a ser desenvolvido com o ensino da Matemática na Educação Infantil, Ensino Fundamental e Médio é um desafio aos professores e gestores das instituições educacionais. A Base Nacional Comum Curricular (BNCC) começa o tópico da área de Matemática afirmando que "o conhecimento matemático é necessário para todos os alunos daEducação Básica, seja por sua grande aplicação na sociedade contemporânea,seja pelas suas potencialidades na formação de cidadãoscríticos, cientes de suas responsabilidades sociais" (BRASIL, 2018, p. 265). Porém, nesse contexto de Educação Matemática para todos questiona-se como ela está acontecendo para grupos minoritários, como os surdos, por exemplo?

Muniz (2016) salienta que toda criança tem capacidade de aprender, pois é um ser matemático e, se está com dificuldades para aprender, alguma coisa aconteceu ao longo de sua vida que a levou a isso. Complementa, ainda, que 
[...] para uma dada tarefa matemática ofertada a duas crianças, não há, em absoluto, duas experiências idênticas, ao contrário, a realização da tarefa caracteriza-se pela diversidade da experiência, não apenas pela possibilidade de produção diversa de esquemas mentais" (MUNIZ, 2016. p. 5).

Martins e Santos (2018) destacam a necessidade de uma discussão contínua sobre o ensino da Matemática, visto que atualmente ainda são muitos os problemas enfrentados no cotidiano da sala de aula.A falta de contextualização dos conteúdos à realidade dos alunos, da escola e/ou do meio social no qual convivem, muitas vezes promove essa educação que pouco ou nada atrai crianças e jovens. Agregado a isto se sobressai também a desmotivação de alunos, professores e gestores, a falta de estrutura física, tecnológica e/ou pedagógica, entre outros fatores.

As dificuldades enfrentadas pelos alunos ouvintes no aprendizado de Matemática são, normalmente, as mesmas enfrentadas pelos alunos surdos usuários da Língua Brasileira de Sinais (Libras), contudo, com um agravante: a falta de uma língua em comum entre estudantes e docentes na maioria dos casos, visto a falta de domínio da Libras pelo professor para uma comunicação direta com o aluno.

A Lei $N^{\circ}$ 10.436, de 24 de abril de 2002 (BRASIL, 2002) dispõe sobre a Língua Brasileira de Sinais, onde já no seu primeiro artigo define:

Art. 1 o É reconhecida como meio legal de comunicação e expressão a Língua Brasileira de Sinais - Libras e outros recursos de expressão a ela associados. Parágrafo único. Entende-se como Língua Brasileira de Sinais - Libras a forma de comunicação e expressão, em que o sistema linguístico de natureza visual-motora, com estrutura gramatical própria, constituem um sistema linguístico de transmissão de ideias e fatos, oriundos de comunidades de pessoas surdas do Brasil.

Essa lei foi regulamentada pelo Decreto No 5.626, de 22 de dezembro de 2005 (BRASIL, 2005). O referido Decreto garante o direito à educação das pessoas surdas em escolas e classes de educação bilíngue, abertas a alunos surdos e ouvintes, com professores bilíngues, na Educação Infantil e nos anos iniciais do Ensino Fundamental. Para o Decreto, no segundo artigo, “[...] considera-se pessoa surda aquela que, por ter perda auditiva, compreende e interage com o mundo por meio de experiências visuais, manifestando sua cultura principalmente pelo uso da Língua Brasileira de Sinais - Libras” (BRASIL, 2005).

Neste mesmo decreto, no artigo 22,são denominadas escolas ou classes de educação bilíngue aquelas em que a Libras e a modalidade escrita da Língua Portuguesa sejam línguas de instrução utilizadas no desenvolvimento de todo o processo educativo (BRASIL, 2005). 
Sabe-se, entretanto, que são poucos os professores de Matemática com formação especializada que lhes permita docência da Matemática em Libras. Além disso, os cursos de Licenciatura em Matemática, assim como as demais licenciaturas, carecem de disciplinas que ofereçam ao licenciado conhecimentos e práticas sobre a docência para estudantes surdos. A disciplina obrigatória de Libras, que surgiu a partir do Decreto $N^{\circ} 5.626$ (BRASIL, 2005) não consegue suprir toda a demanda de formação de um professor de Matemática para Surdos, até porque nela geralmente é dado foco na Libras em si, enquanto língua, e não no processo de ensinar um aluno surdo a partir dela.

Nesse cenário, a pesquisa realizada por Araujo (2015, p. 31) teve como objetivo "analisar o desenvolvimento profissional do pesquisador no ensino de matemática em Libras como primeira língua para alunos surdos, e (re)construir suas práticas pedagógicas diante desse processo, à luz da aprendizagem dos alunos", onde fica evidente que os professores estão preocupados com esse processo de ensinar a Matemática à comunidade surda.

De forma similar àpesquisa de Araujo (2015), este texto relata uma das experiências da pesquisa realizadano projeto "Produção de videoaulas de Matemática com tradução em Libras", denominado "MathLibras", resultante do Edital sobre Tecnologia Assistiva (Chamada CNPq/MCTIC/SECIS No 20/2016), o qual recebeu financiamento do Conselho Nacional de Desenvolvimento Científico e Tecnológico (CNPq), desenvolvida junto ao Instituto de Física e Matemática (IFM) da Universidade Federal de Pelotas (UFPel).

O objetivo principal da pesquisa foi produzir vídeos de Matemática básica em Libras, tencionando a proposta em como ensinar Matemática para alunos surdos de forma a privilegiar o ensino em sua primeira língua, a Libras, e em como agregar a tecnologia de forma positiva nesse processo.

O financiamento do CNPq abrangeu o período entre Junho de 2017 a Junho de 2019, porém o MathLibrassegue em atividade na UFPel. É uma parceria entre o Departamento de Educação Matemática (DEMAT), do IFM, e a área de Libras do Centro de Letras e Comunicação (CLC). Atualmente conta com a participação voluntária de professores, intérpretes, acadêmicos e mestrandos. No período de vigência junto ao $\mathrm{CNPq}$ teve alunos bolsistas, dos cursos de Cinema e Audiovisual, Cinema e Animação, Design Digital e Licenciatura em Matemática.

Contextualizado o MathLibras, neste artigoo objetivo é apresentar e analisar dois vídeos produzidos em 2018, sobre o conteúdo de frações, já disponibilizados no canal do projeto no 
Youtube $^{1}$.A fundamentação do trabalho é a partir da Pedagogia Visual, explicada no próximo tópico.

\section{A Pedagogia Visual na Educação Matemática dos surdos}

Para demarcar o campo de pesquisa procurou-se por trabalhos na área da Educação Matemática vinculados à Educação de Surdos, buscando conhecer o que está sendo feito na área. Deste modo, trabalhos como o de Araujo (2015), Borges (2013), Moura (2015), Nogueira (2013), Nunes et al (2013), Silva $(2008 ; 2010)$ e Viana e Barreto (2014) foram alguns dos referências iniciais para o MathLibras.

No cotidiano escolar o professor dos alunos surdos precisa considerar suas singularidades de apreensão e construção de sentidos e que, pelo pouco acesso à mídia de forma completa, na maioria dos casos, este conhecimento geral é reduzido quando comparado aos alunos ouvintes, conforme frisam Lacerda, Santos e Caetano (2014).

Nunes et al (2013) apresentam pesquisas nas quais a defasagem das crianças surdas em Matemática talvez possa ser explicada exatamente pelo restrito número de interações com aquilo que as cerca, os quais deveriam estimular o desenvolvimento do raciocínio matemático antes de seu ingresso no ambiente formal da escola.

Outras dificuldades podem surgir de dois fenômenos, além dessa restrição de interações linguístico-matemáticas: i) o desconhecimento de estratégias e recursos visuais para o ensino dos surdos (LEBEDEFF, 2010), o que configuraria uma Pedagogia Visual para Surdos (LACERDA; SANTOS; CAETANO, 2014) e ii) o desconhecimento ou a inexistência de sinais específicos da área que pedem "combinados diários" de um novo léxico que pode, eventualmente, ser trocado por um novo professor ou por um outro Tradutor Intérprete de Língua de Sinais (TILS), discutido por Abreu (2016) em sua Dissertação.

Por outro lado, Nunes et al (2013) salientam que diversos estudos mostram, igualmente, a possibilidade de promover a compreensão de conceitos matemáticos entre as crianças surdas através de intervenções especificamente planejadas para elas. A Pedagogia Visual, que é uma possibilidade de intervenção planejada para pessoas surdas, tem a ver com a necessidade de que os processos educativos que envolvem alunos surdos implementem estratégias ou atividades visuais.

\footnotetext{
${ }^{1}$ Canal do Mathlibras: https://www.youtube.com/channel/UC7rtwOJBv4c4PyIhSFvg3Hg/videos.
} 
Sobre Experiência Visual Lebedeff (2017) comenta que o conceito tem relação com as possibilidades de interação e compreensão do mundo, pelos surdos, por meio da visão. A autora salienta que não é uma situação biológica de compensação, mas sim, uma organização linguística, cognitiva e cultural das pessoas surdas. Artefatos culturais que privilegiam a visão, tais como as Línguas de Sinais, o Letramento Visual, as modificações arquitetônicas, as inovações tecnológicas, entre outros, são desenvolvidos, portanto, pela e para a comunidade surda, para dar conta da interação no mundo e compreensão deste próprio mundo que prescinde de som. A autora propõe, ainda, a necessidade do tensionamento de uma "visualidade aplicada", ou seja, que as práticas pedagógicas, os artefatos tecnológicos, as arquiteturas curriculares, entre outros, sejam problematizados e propostos a partir da compreensão da experiência visual.

Nesse sentido, Lacerda, Santos e Caetano (2014, p. 186) discutem que é necessário "pensar em uma Pedagogia que atenda as necessidades dos alunos surdos que se encontram imersos no mundo visual. e apreendem, a partir dele, a maior parte das informações para a construção do seu conhecimento". De acordo com as autoras, não basta apenas apresentar os conteúdos em Libras, é necessário explicar os conteúdos, em sala de aula, utilizando a potencialidade visual intrínseca à Libras.

Cabe discutir aqui, também, o conceito de "textualidade diferida" que embasa a produção dos vídeos. Para Peluso (2015) os vídeos podem ser uma forma alternativa para a escrita. Entretanto, faz referência a um tipo de especialização que ocorre nas estruturas e funções da gravação das línguas de sinais, que se diferenciam da forma e função, de uma maneira geral, de outros produtos audiovisuais, tais como filme, documentários, entre outros. Os textos gravados em vídeo, em línguas de sinais, tem como centro absoluto o texto linguístico e o seupapel é funcionar como um "texto diferido". São vídeos nos quais fica privilegiado o falante realizando os seus discursos.

De acordo com o exposto, numa tentativa de propor recursos pautados na Pedagogia Visual utilizando textualidade diferida, o objetivo principal do MathLibras é produzir vídeos que possibilitem a compreensão de Matemática básica, utilizando a Libras como língua de instrução e produção textual e, utilizar recursos e estratégias visuais para explicar conceitos, algoritmos, entre outros, os quais poderão auxiliar os alunos surdos no processo de aprendizagem e compreensão dos conteúdos matemáticos. Os vídeos possuem animações simples e buscam uma identificação visual com as crianças através da interação dos atores/apresentadores com dois personagens infantis: a Sara e o Levi, que serão apresentados mais adiante. 
A investigação caracteriza-se como uma Pesquisa Aplicada, que, de acordo com Damiani et al (2013) têm como finalidade contribuir para a solução de problemas práticos. Nesse sentido, o objetivo principal é produzir os vídeos e, ao oferecê-los aos alunos surdos, preencher lacunas que emergem das dificuldades acima citadas. Para tal, leva-se em consideração que: a) os vídeos são gravados em Libras como língua de instrução, discutindo o léxico específico por surdos, professores da área de Libras, TILS com formação pedagógica e professores de Matemática ouvintes e bilíngues e, b) os vídeos apresentam a explicação do conteúdo contextualizada, a partir de histórias vinculadas às situações reais do cotidiano do aluno, proporcionando condições para a construção de conceitos.

\section{O MathLibras constituído como uma equipe multidisciplinar}

O MathLibrasé constituído por um grupo multidisciplinar. Sua origem se deu a partir do diálogo entre professoras dos Programas de Pós-Graduação em Educação Matemática (PPGEMAT) e Letras (PPGL), ambos da UFPel. Agregaram-se ao projeto vários parceiros, vindos da Área de Libras da instituição, do Núcleo da Acessibilidade e Inclusão (NAI) da UFPel, vinculados à Seção de Tradutores Intérpretes de Libras e da Escola Especial Professor Alfredo Dub, escola com uma proposta bilíngue de ensino para alunos surdos e, também com surdocegueira, com 70 anos de atuação no município de Pelotas, Rio Grande do Sul (RS).

Devido à possibilidade de bolsas durante a vigência do projeto junto ao $\mathrm{CNPq}$, o MathLibras constituiu um corpo de bolsistas, acadêmicos nas áreas de Cinema e Animação, Cinema e Audiovisual, Design Digital e Licenciatura em Matemática. Cada um atuava conforme sua formação, porém nos momentos de reunião geral as especificidades conversavam em conjunto, visando o coletivo proposto. Salienta-se que, conforme as normativas do CNPq, não houve um bolsista que fosse acadêmico da UFPel e Tradutor Intérprete da Língua de Sinais (TILS) para compor a equipe, desta forma, o processo de tradução é feito todo de forma voluntária.

Em 2018, o grupo reunia-se uma vez por semana para a discussão de roteiros, estudo e gravação, no turno da manhã nas segundas-feiras. No primeiro semestre de 2019 os encontros aconteciam em dois momentos, segundas e quartas pela manhã, conforme a disponibilidade das duplas de gravação: professor surdo e intérprete. Agora no segundo semestre de 2019 os horários foram alterados e momentaneamente as gravações estão suspensas, pois os horários entre os professores surdos e os intérpretes não combinam. 
As demais etapas, de gravação do áudio, edição e animação, são realizadas em outros horários, de acordo com as atribuições de cada um. O processo todo passa por um longo caminho, desde a escrita inicial do roteiro com a história matemática a ser contada, até a sua finalização, para publicação no canal do YouTube. Na produção são muitas etapas, e todas interligadas, tais como a definição de sinais, gravaçãoem Libras e sua validação, gravação de áudio, inserção das animações e da legenda. O espaço do projeto é uma pequena sala que serve de estúdio e ambiente para as demais atividades.

Estando com as gravações suspensas, as acadêmicas da área de Cinema e Audiovisual e Design Digital, ex-bolsistas e voluntárias até o fim do ano, estão em processo de finalização de outros vídeos já gravados.

\section{As videoaulas do MathLibras sofre frações}

Buscam-se por opções no âmbito educacional para proporcionar um ensino que de fato chegue até o aluno imerso no mundo digital, considerando que "[...] a forma acelerada com que inovações tecnológicas vêm tomando corpo é, atualmente, uma característica marcante de nossa sociedade" (BORBA; SILVA; GADANIDIS, 2018, p. 21).

Atrelado ao mundo digital, que está posto no século XXI, ao pensar na Educação de Surdos um dos principais objetivos e grande desafio dos professores é oportunizar a aquisição de Libras de forma natural ao aluno surdo (MOURA, 2014).

Uma criança ouvinte adquire sua primeira língua (L1) de forma natural e espontânea, desde o nascimento, em ambiente não formal de aprendizagem, como o lar (QUADROS, 1997). Essa autora argumenta que ninguém ensina "formalmente" ninguém a falar, puramente se aprende a falar ouvindo os outros, pela imersão e pela repetição. Com as crianças surdas, filhas de pais surdos, o processo é similar. Elas não são ensinadas formalmente a sinalizar, porém, pela imersão, visualização e repetição, de forma natural, vão aprendendo, pois isto faz parte do seu dia-a-dia.

Entretanto, há uma diferença nesta situação se os pais são ouvintes e a criança surda, e não há nenhum outro surdo na família. Nesse panorama, é provável que o ensino da Língua de Sinais fique sob a responsabilidade inicial da escola ou, no melhor dos casos (o que é esperado), após os pais e/ou responsáveis aprenderem a mesma para se comunicar com seu filho.

O aluno surdo tem o direito linguístico de ter acesso ao conhecimento, incluindo a Matemática e qualquer outra disciplina escolar, em sua língua natural, a Libras (SKLIAR, 
2016). Ainda, de conviver em um ambiente escolar que utilize as tecnologias digitais disponíveis socialmente. Assim, o MathLibrasfoi estruturado para produzir vídeos com a Libras como protagonista, oportunizando aos alunos surdos conteúdos de Matemática em sua L1, objetivando uma melhor aprendizagem, tendo como pressuposto que a Libras é a língua de instrução da criança surda e não apenas um recurso de acessibilidade.

A videoaula no MathLibras foi concebida a partir da inserção da tecnologia no processo de aprendizagem, de forma a considerá-la como um recurso de ensino para os surdos, visando melhorar sua aprendizagem, autonomia e inserção social. Nesse sentido, "os vídeos digitais, que podem ser concebidos enquanto narrativas ou textos multimodais, compilam diversos modos de comunicação como oralidade, escrita, imagens dinâmicas, espaços, formas de gestualidade e movimentos, etc.” (BORBA; SILVA; GADANIDIS, 2018, p. 34).

Sendo a Libras uma língua visogestual, a Pedagogia Visual foi referência nesse processo, sendo definida, a partir de Campello (2007), como a

[...] exploração de várias nuances, ricas e inexploradas, da imagem, signo, significado e semiótica visual na prática educacional cotidiana, procurando oferecer subsídios para melhorar e ampliar o leque dos "olhares" aos sujeitos surdos e sua capacidade de captar e compreender o "saber" e a "abstração" do pensamento imagético dos surdos. (CAMPELLO, 2007, p. 130).

O MathLibras está sendo desenvolvido de forma a respeitar a diferença linguística e cultural que o aluno surdo tem (STROBEL, 2009) oportunizando o aprendizado da Matemática em sua língua natural e, ao mesmo tempo, estimulando-o a aperfeiçoá-la a partir de situações cotidianas em que os números estão inseridos.

Entre os anos de 2017 e 2018 foram produzidos sete vídeos, descritos no Quadro 1, onde aparecem o título, o conteúdo abordado, o objetivo e a data de postagem no canal do MathLibras no YouTube.

Quadro 1: Primeiros sete vídeos.

\begin{tabular}{|c|c|c|c|}
\hline Nome do vídeo & Conteúdo & Objetivo & Postagem no YouTube \\
\hline Classificar pra quê - Aula 1 & \multirow{4}{*}{ Classificação } & \multirow{4}{*}{$\begin{array}{c}\text { Desenvolver o } \\
\text { conceito de } \\
\text { classificação, } \\
\text { visando a formação } \\
\text { do professor. }\end{array}$} & \multirow{2}{*}{04 de junho de 2018} \\
\hline Classificar pra quê - Aula 2 & & & \\
\hline Classificar pra quê - Aula 3 & & & \multirow{2}{*}{06 de junho de 2018} \\
\hline Classificar pra quê - Aula 4 & & & \\
\hline Adição em Libras - Soma 9 & \multirow{3}{*}{ Adição } & \multirow{3}{*}{$\begin{array}{c}\text { Explorar o conceito } \\
\text { de adição }\end{array}$} & \multirow{3}{*}{15 de outubro de 2018} \\
\hline Adição em Libras - Soma 8 & & & \\
\hline Adição em Libras - Soma 3 & & & \\
\hline
\end{tabular}

Fonte: As pesquisadoras, 2019. 
Os primeiros sete vídeos, conforme o Quadro 1, foram organizadas num viés “ouvinte", onde primeiro foi gravado o áudio para depois a tradução para a Libras, mesmo que a imagem do ator surdo ou intérprete estivesse em destaque no vídeo. Os conteúdos escolhidos foram pensados para atender as demandas dos professores e alunos da Escola Alfredo Dub, conforme solicitado dos docentes da escola. Optou-se pelo conceito de adição, sem agrupamento, para os alunos dos anos iniciais da Educação Básica, e, ainda, uma coleção de vídeos pedagógicos, sobre o conceito de classificação (LORENZATO, 2006; RAMOS, 2009), que auxiliano processo de construção do conceito de número, direcionada para os professores. Nestes vídeos havia animação, porém não havia legenda.

Projetando uma identificação visual dos alunos surdos com as histórias do MathLibras, foram criados pela bolsista do Cinema e Animação, dois personagens, o Levi e a Sara (Figura 1). Nos vídeos produzidos para os alunos os personagens vivenciam uma história e apresentam um problema matemático, para o qual necessitam de ajuda na resolução.

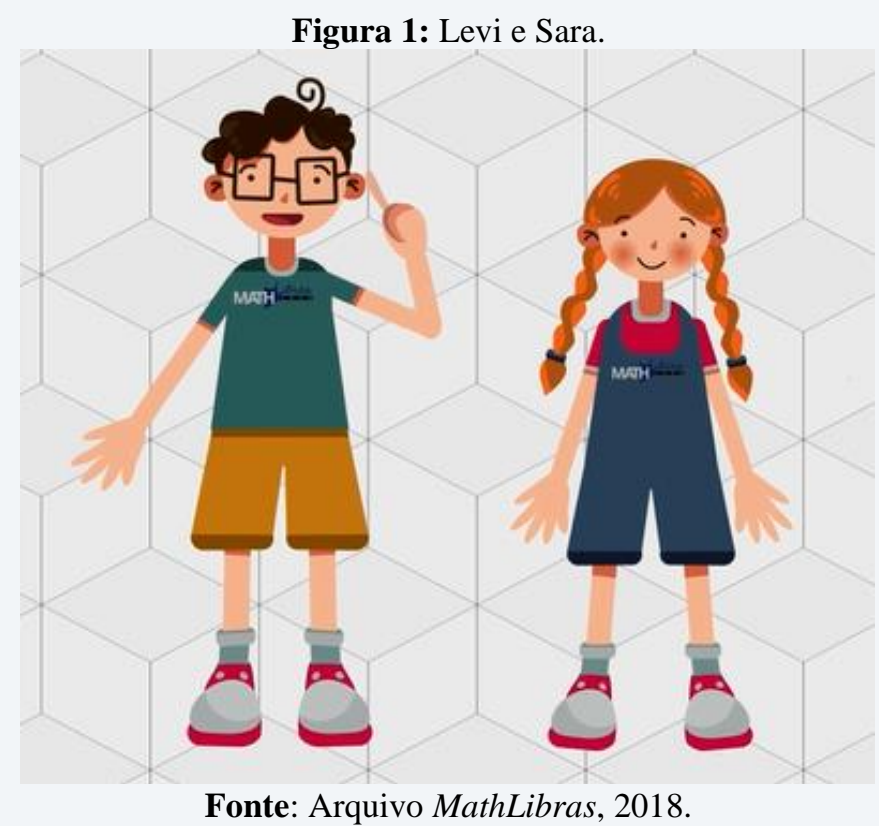

Como o trabalho focaliza em uma perspectiva de Experiência Visual (LEBEDEFF, 2017), Pedagogia Visual (LACERDA; SANTOS; CAETANO, 2014; CAMPELLO, 2008) e na Textualidade Diferida (PELUSO, 2015) nos vídeos do MathLibras são utilizados personagens e animações que contextualizam a explicação do conceito matemático. Assim, as videoaulas abordam uma história, contada somente em Libras e, com o áudio gravado "em off”, pensado 
para pais e professores e demais interessados na área que não tenham conhecimento/domínio da língua.

Para avaliação destes primeiros vídeos produzidos, um grupo de três professoras do MathLibras, junto com uma das intérpretes, realizou uma visita técnica ao Instituto Nacional de Educação de Surdos (INES), antes de dar continuidade às gravações. Na visita buscou-se pela experiência de quem trabalha com Educação de Surdos há muito tempo. Assim, visitou-se o Grupo de Pesquisa Educação, Mídias e Comunidade Surda no Departamento de Ensino Superior do INES e a TV INES.

Consolidando o trabalho, ao retornar da visita ao INES algumas modificações foram feitas, entre elas destacam-se: a gravação da Libras é feita primeiro e só depois de validada se grava o áudio, a partir do trabalho de tradução da Libras para o português. Quando Libras e áudio estão em sintonia é iniciado o processo de animação e legendagem. Nesta nova etapa, já foram finalizados mais seis vídeos, conforme o Quadro 2 a seguir.

Quadro 2: Seis vídeos.

\begin{tabular}{|c|c|c|c|}
\hline Vídeo & Conteúdo & Objetivo & Postagem no canal \\
\hline Fração em Libras - Aula 1 & \multirow{2}{*}{ Fração } & \multirow{2}{*}{$\begin{array}{l}\text { Explorar o conceito de } \\
\text { fração. }\end{array}$} & \multirow{2}{*}{23 de novembro de 2018} \\
\hline Fração em Libras - Aula 2 & & & \\
\hline Subtração em Libras - Subtração 2 & \multirow{3}{*}{ Subtração } & \multirow{3}{*}{$\begin{array}{l}\text { Explorar o conceito de } \\
\text { subtração. }\end{array}$} & 18 de dezembro de 2018 \\
\hline Subtração em Libras - Subtração 7 & & & 08 de abril de 2019 \\
\hline Subtração em Libras - Subtração 6 & & & 05 de junho de 2019 \\
\hline Adição em Libras - Soma 7 & Adição & $\begin{array}{l}\text { Explorar o conceito de } \\
\text { adição. }\end{array}$ & 05 de junho de 2019 \\
\hline
\end{tabular}

Fonte: As pesquisadoras, 2019.

Destes vídeos, aqui neste texto faremos uma análise sobre as duas videoaulas sobre frações. Estas foram gravadas pela intérprete do projeto, e foram validades pela equipe de professores da área de Libras, surdos e ouvintes, bem como pela equipe da Matemática.

A proposta de começar a gravar videoaulas com o conteúdo de frações vem de um anseio antigo, pois o conteúdo de frações é temido por alunos e, muitas vezes, pelos próprios professores dos anos iniciais do Ensino Fundamental.

O objetivo das duas videoaulas já finalizadas é apresentar as frações, trabalhando com sua representação imagética (com figuras), em linguagem matemática e em língua portuguesa, a partir de sua leitura, além da sua representação em Libras. É importante que o aluno surdo comece se familiarizando com o básico para que em futuras aulas, com o conteúdo mais 
avançado, sejam "capazes de compreender a utilização e as necessidades práticas cotidianas" (SILVA et al, 2018, p. 1) das frações.

Fração em Libras ${ }^{2}$ - Aula 1 começa questionando os alunos se eles conhecem e sabem calcular frações. A palavra F-R-A-Ç-Ã-O, escrita dessa forma, significa que a intérprete fez soletração, em alfabeto manual, da palavra(Figura 2). O Alfabeto Manual, de acordo com Nascimento (2011) é a correspondência deuma letra da grafia de uma língua oral com uma configuração de mão $(\mathrm{CM})$ de uma língua de sinais, às vezes acrescida de movimento, sendo que a soletração manual tem sido um canal produtivo para empréstimos entre línguas orais e línguas de sinais.

Figura 2: Datilologia de frações

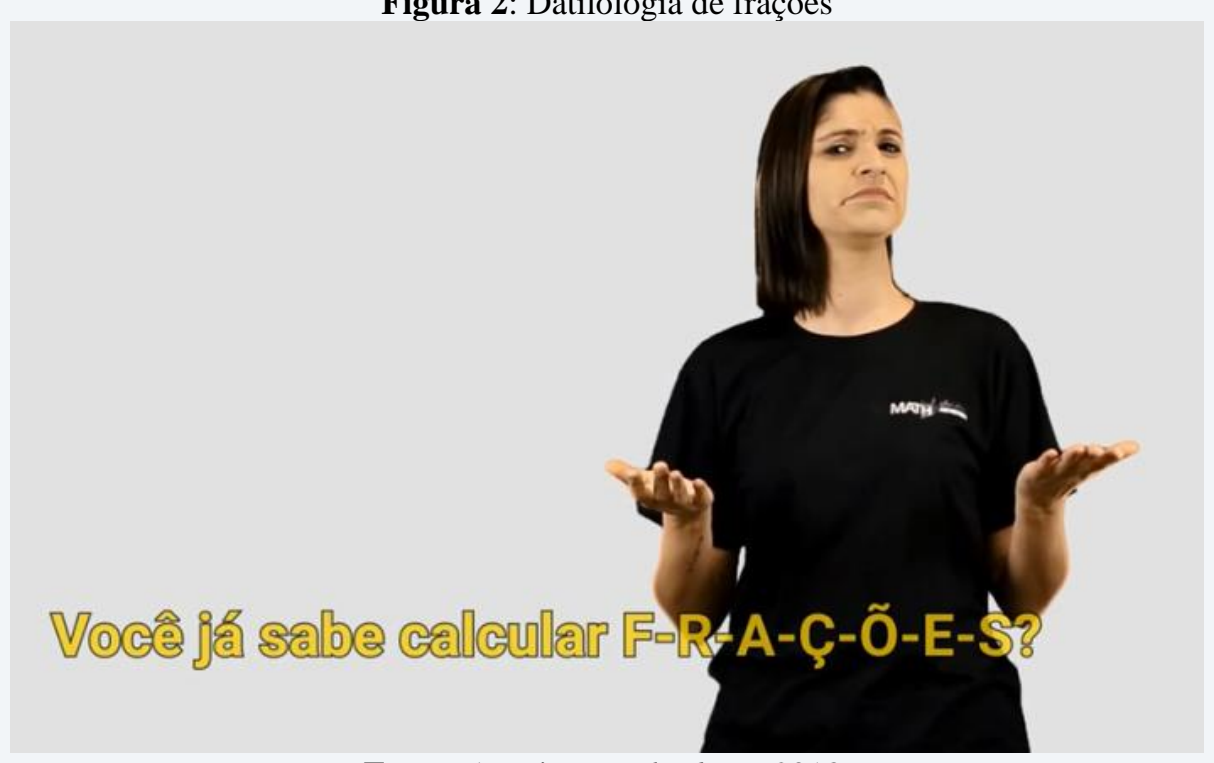

Fonte: Arquivo MathLibras, 2018.

A soletração da palavra, em alfabeto manual,oportuniza ao aluno surdo conhecer a grafia das palavras em língua portuguesa, que no ensino bilíngue será a sua segunda língua, na forma escrita. Logo após apresentar a palavra a intérprete faz o sinal de frações (Figura 3) que foi adotado pela equipe do MathLibras.

\footnotetext{
${ }^{2}$ Disponível em: https://www.youtube.com/watch?v=UPp4JeiDJls\&t=312s.
} 
Figura 3: Sinal de frações em Libras.

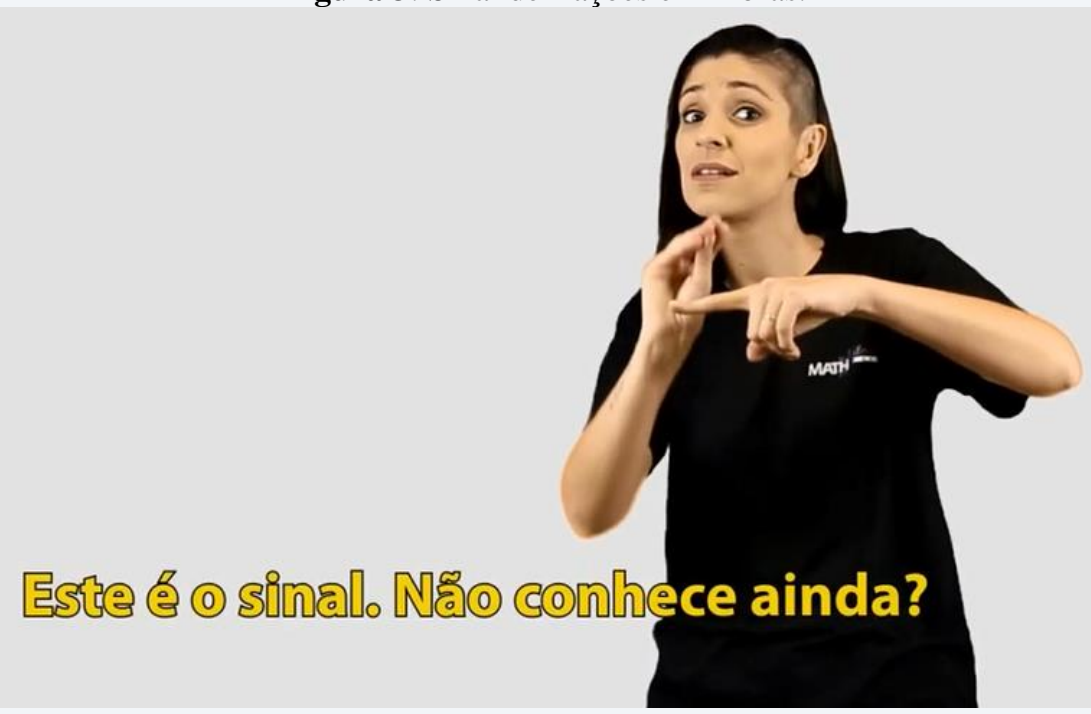

Fonte: Arquivo MathLibras, 2018.

Smole e Diniz (2016) afirmam que o conteúdo de frações deve ser planejado para ser ensinado ao longo do ano, normalmente a partir do $4^{\circ}$ ou $5^{\circ}$ ano do Ensino Fundamental. As autoras ainda destacam a importância dos alunos conhecerem os principais significados que a fração representa: "fração como parte de um todo, fração como resultado de uma divisão e fração como razão" (SMOLE; DINIZ, 2016, p. 25).

Nesse primeiro vídeo a construção da ideia de fração é a partir de um retângulo de papel, com o significado de fração como parte de um todo. A proposta é que os alunos possam acompanhar o vídeo imitando a intérprete, ou seja, reproduzindo os movimentos com o seu próprio retângulo.

É apresentado o retângulo como o I-N-T-E-I-R-O (Figura 4), a partir do qual serão realizadas as divisões, representadas no papel pelo número de dobras.

Figura 4: $\mathrm{O}$ inteiro.

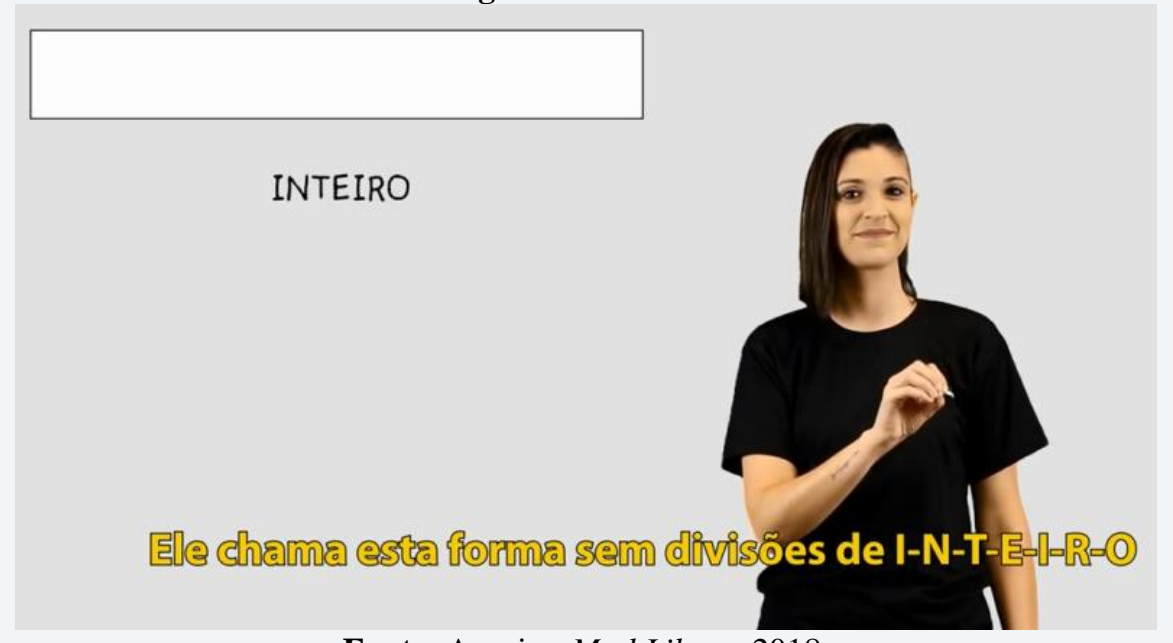

Fonte: Arquivo MathLibras, 2018. 
A primeira ação é dobrar o papel ao meio, e depois abri-lo novamente. O inteiro fica com uma marcação, e tem-se a partir daí a representação da metade, ou do meio $\left(\frac{1}{2}\right)$. A cada dobra pinta-se somente uma das marcações, de forma que as frações representadas tem o numerador um (parte acima da fração) e o denominador conforme o número de dobras, neste primeiro caso, o dois.

Na sequência Levi, o personagem envolvido neste vídeo, quer fazer mais uma dobra a partir da que já foi feita. Então, a intérprete dobra o papel duas vezes e, ao abrir, observa que o papel agora tem quatro marcas, ou seja, foi dividido em quatro partes (Figura 5).

Figura 5: O inteiro dividido em quatro partes.

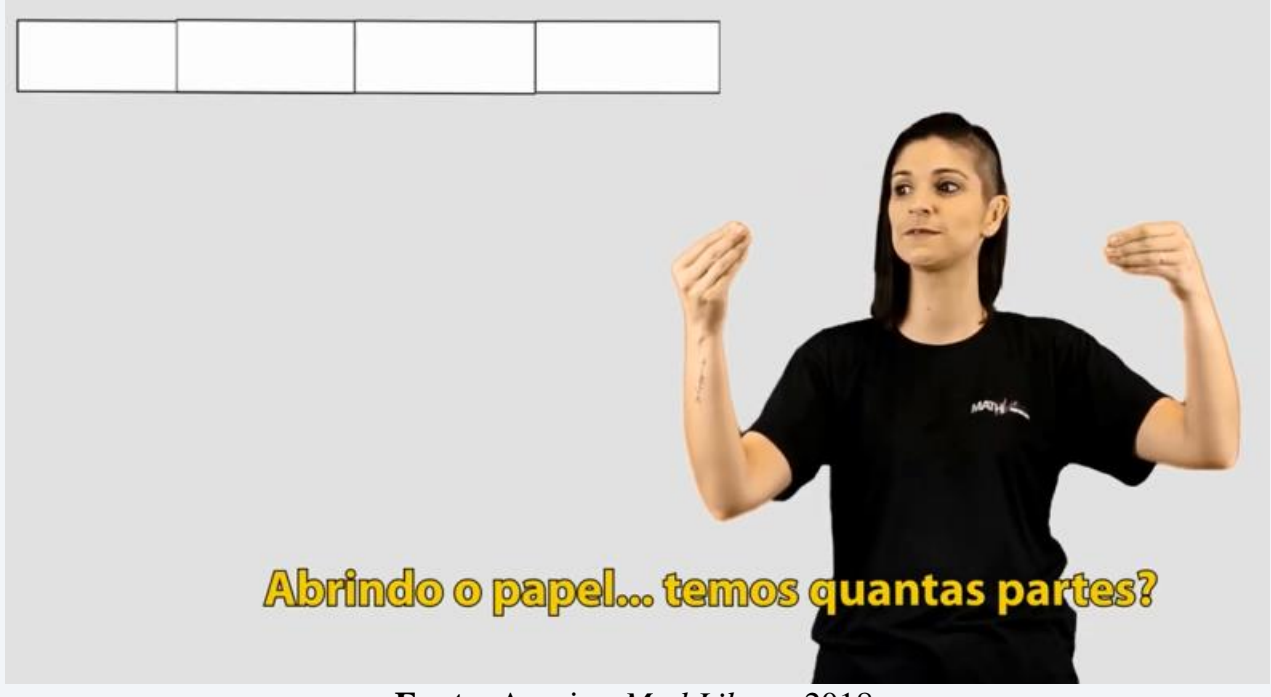

Fonte: Arquivo MathLibras, 2018.

Então, para confirmar a divisão realizada e buscando a linguagem visual, a intérprete faz a contagem das partes. A cada pedaço contado, o mesmo aparece em azul, fazendo a relação.

Figura 6: Contagem das quatro partes.

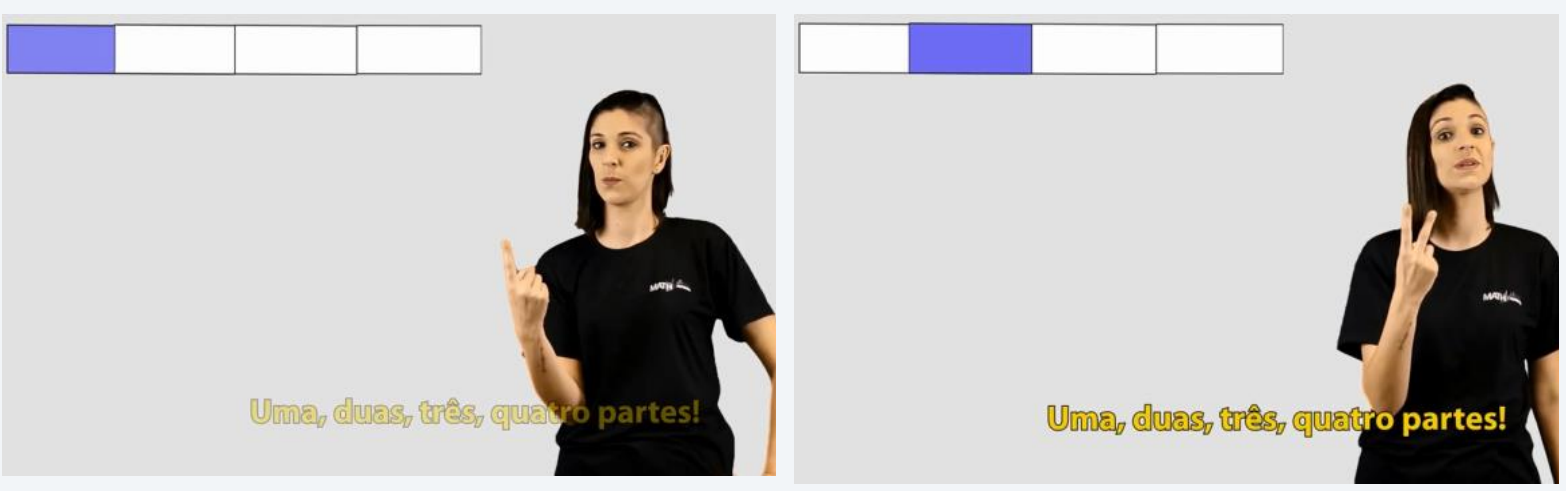



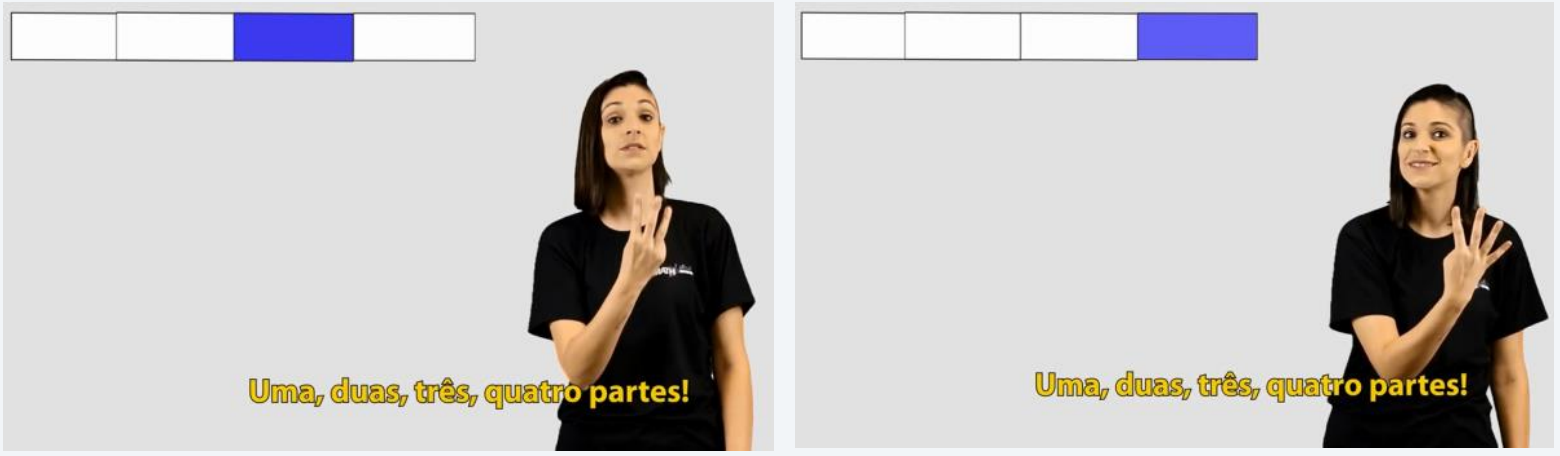

Fonte: Arquivo MathLibras, 2018.

Finalizada a contagem, de forma a confirmar com o telespectador que a divisão foi realizada em quatro partes, o questionamento é referente à qual a fração que corresponde a uma parte pintada de azul.

Figura 7: Qual a fração para a parte pintada?

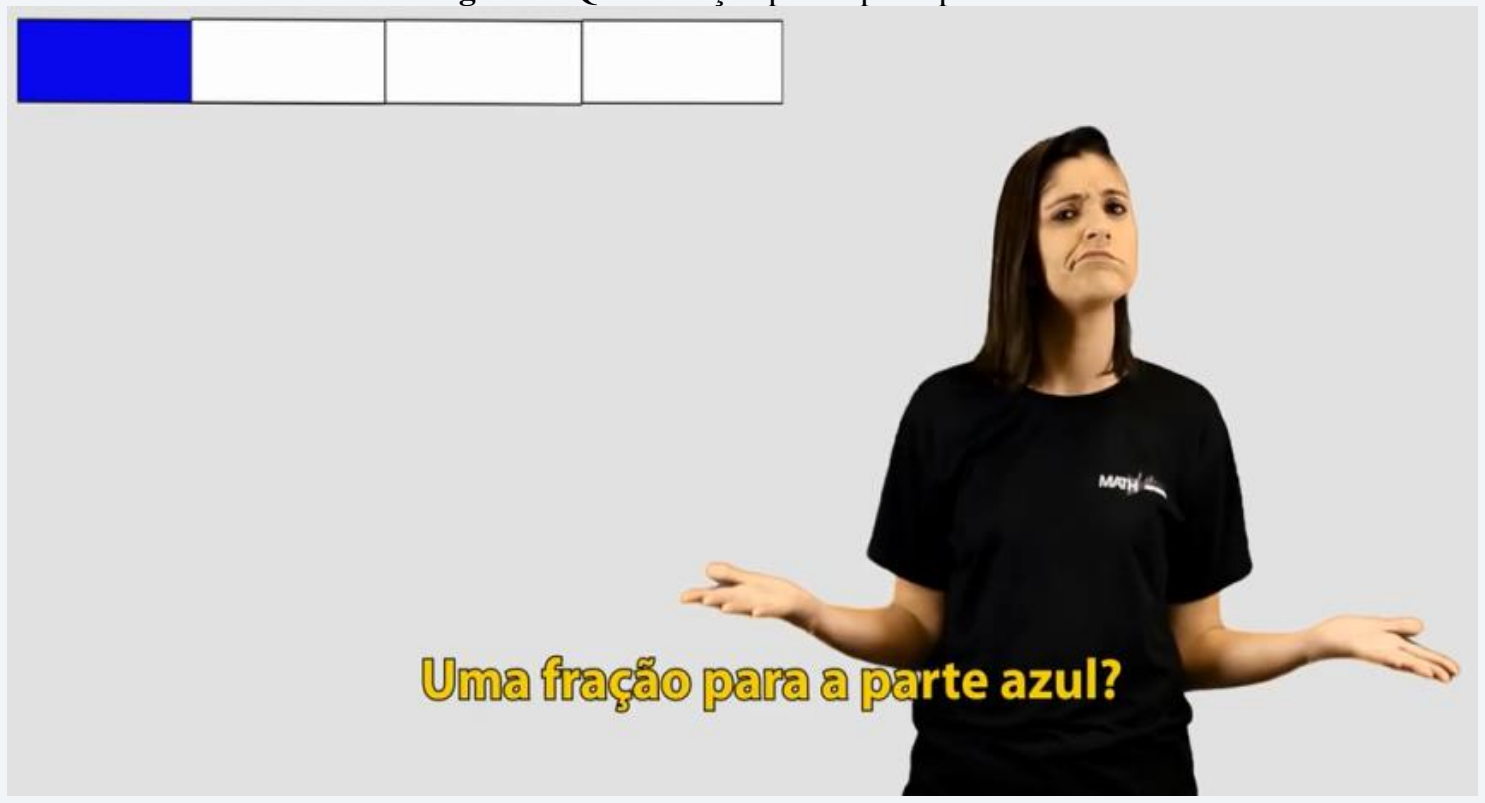

Fonte: Arquivo MathLibras, 2018.

Considerando que um aluno esteja assistindo ao vídeo para aprender ou reforçar o conceito de fração, espera-se que o mesmo esteja dialogando com a intérprete, de forma a respondê-la, em Libras, a partir de seu entendimento. Não demora muito e a resposta é apresentada no vídeo, com a linguagem matemática, $\frac{1}{4}$, e com a escrita em português, onde novamente faz a datilologia para que não fique dúvida sobre a escrita. 
Figura 8: Representação de um quarto.

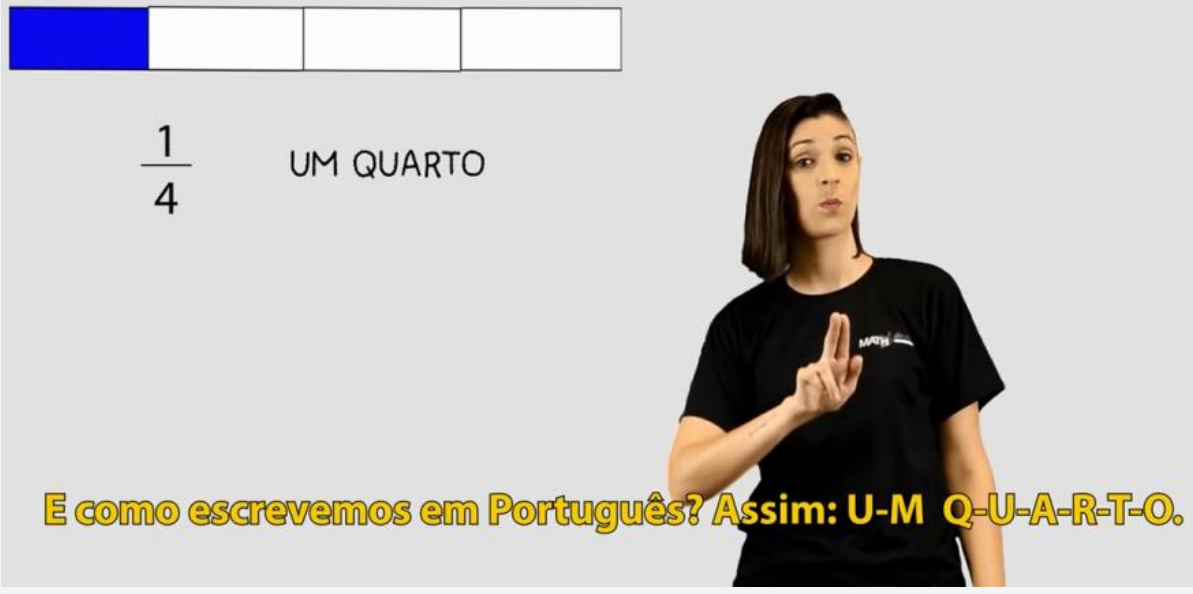

Fonte: Arquivo MathLibras, 2018.

O processo é repetido para o papel dobrado três vezes, gerando oito dobras no papel e a fração $\frac{1}{8}$, correspondendo a uma parte pintada de azul. No final do vídeo a intérprete faz uma recapitulação das dobras realizadas, resgatando a representação matemática e a escrita em português (Figura 9).

Figura 9: Resumo da Aula 1 sobre frações.

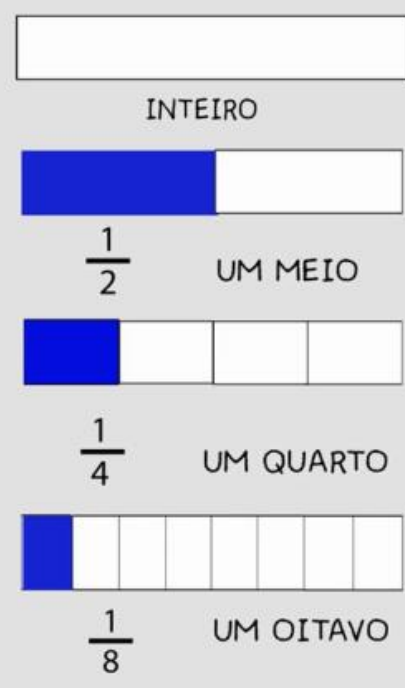

Fonte: Arquivo MathLibras, 2018.

O vídeo é finalizado afirmando: "Esses exemplos nós estudamos com papel, mas podemos pensar as frações cortando, dobrando, separando, distribuindo qualquer tipo de material". Ou seja, a proposta de utilizar as marcações em um retângulo de papel é pela facilidade que o professor tem de reproduzir as dobras com os seus alunos em sala de aula, porém outras tantas formas podem (e devem) ser utilizadas. 
Optou-se por trabalhar com o numerador um neste primeiro vídeo para buscar a compreensão dos alunos sobre o conceito de que aquilo que foi destacado/considerado na fração é o que vai no numerador, sendo o denominador o número de marcações após as dobras realizadas $(2,4$ ou 8 nesta aula).

Em outra momento, quando o professor for falar sobre o conteúdo de potência, poderá resgatar essa videoaula e explorar com os alunos o porquê do papel ter ficado com duas, quatro ou oito marcas, não tendo os valores três e seis, por exemplo, a partir das dobras realizadas.

Observa-se que no vídeo houve a inserção de legenda, etapa obrigatória da edição após a visita ao INES, pois, dentre as várias orientações recebidas, essa se mostrou necessária, visto que tem surdos que gostam de utilizar as legendas como uma forma de ter contato com o Português e, ainda, auxilia os ouvintes que estão no processo de aquisição da Libras.

Fração em Libras ${ }^{3}$ - Aula 2 é uma continuidade da aula 1, porém o aluno consegue acompanhá-la mesmo que não tenha assistido a anterior, de forma a manter certa independência entre os vídeos.

A proposta é utilizar materiais do cotidiano escolar do aluno, para que este possa acompanhar o vídeo e ir trabalhando junto com a intérprete. Nesta aula, utilizou-se o estojo de Levi e os lápis que estavam dentro dele, num total de oito.

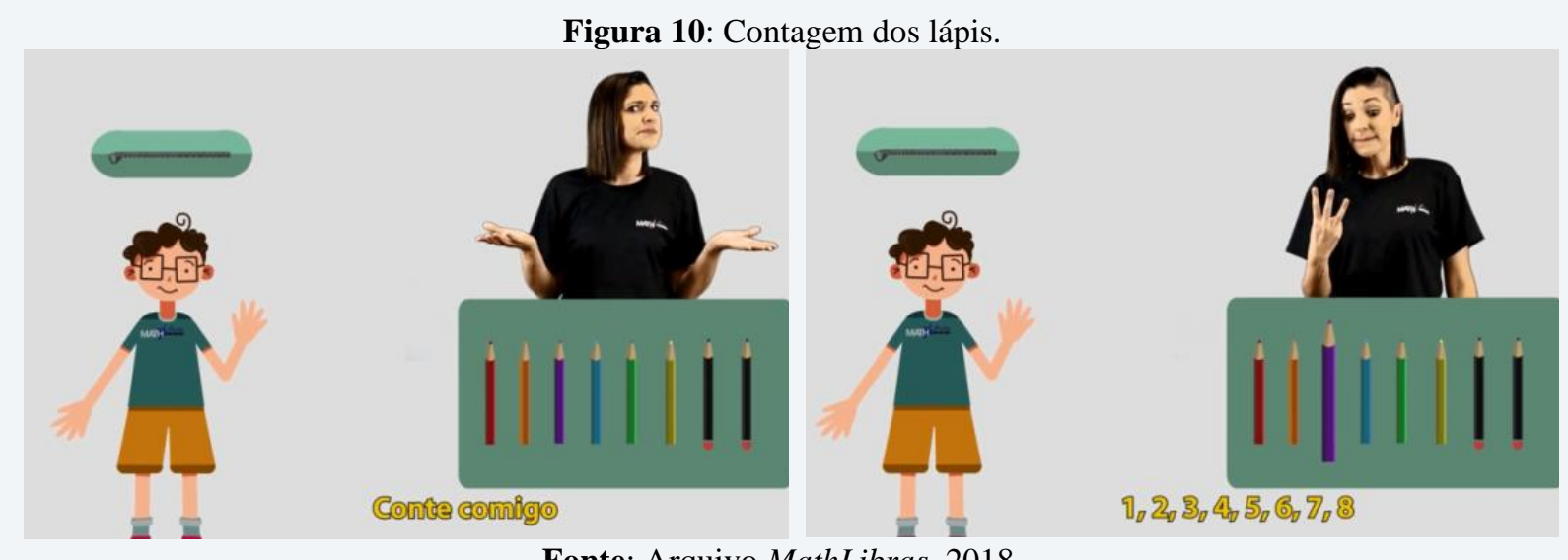

Fonte: Arquivo MathLibras, 2018.

Destaca-se que ao realizar a contagem o lápis correspondente (valor posicional) é destacado na imagem, de modo a auxiliar o aluno na visualização. Após a contagem, a proposta é separar alguns lápis, conforme um critério definido, e ver qual a fração que estes representam em relação ao todo. Importante mencionar que o conceito de classificação é um dos sete

\footnotetext{
${ }^{3}$ Disponível em: https://www.youtube.com/watch?v=EHaptQblnhg.
} 
processos mentais básicos propostos por Lorenzato (2006) para a construção do número, sendo reforçado neste momento.

Optou-se, conforme experiências realizadas com as crianças em sala de aula, em separar os lápis de escrever daqueles que servem para colorir (Figura 11).

Figura 11: Separação dos lápis.

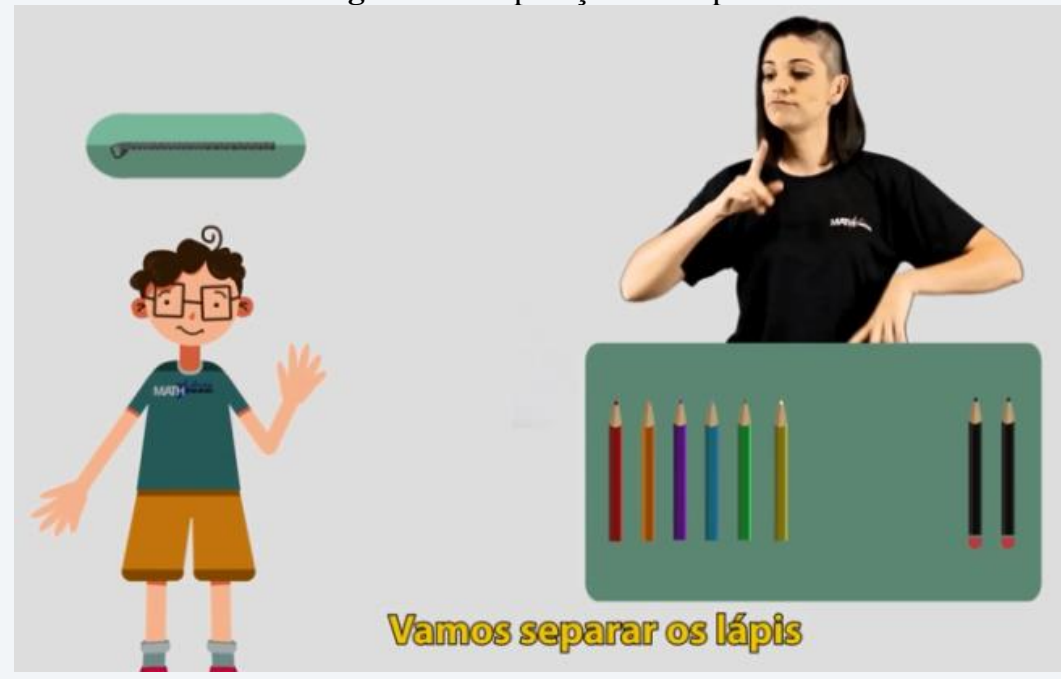

Fonte: Arquivo MathLibras, 2018.

Com a divisão feita, estando de um lado só os coloridos, de pintar, e do outro lado só os pretos, de escrever, a pergunta é: qual a fração que representa os lápis pretos?

Figura 12: Qual a fração que representa os lápis pretos?

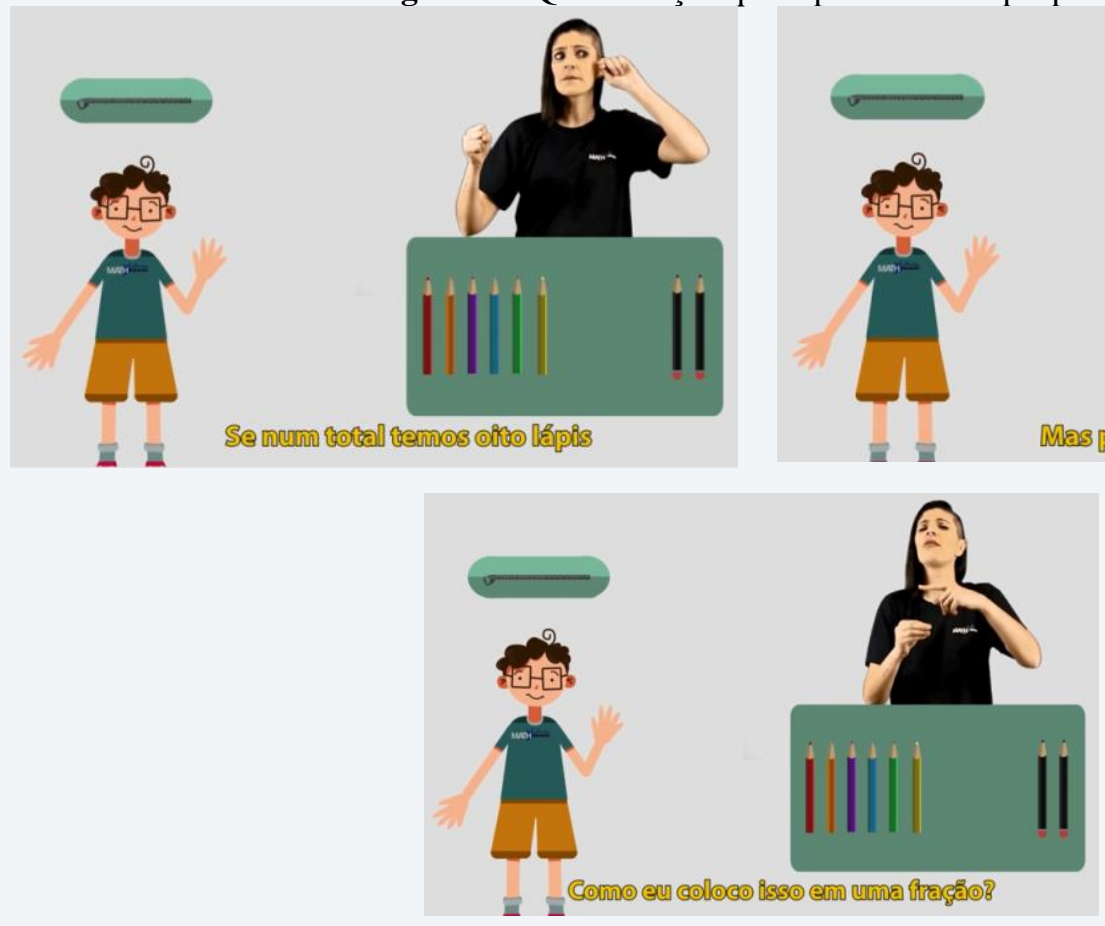

Fonte: Arquivo MathLibras, 2018. 
A construção da fração que representa a parte solicitada é semelhante ao vídeo anterior, e a explicação é feita em detalhes, lembrando que o público principal são alunos surdos do Ensino Fundamental que estejam iniciando o estudo das frações. A intérprete então identifica a fração $\frac{2}{8}$, e depois apresenta sua escrita (Figura 13).

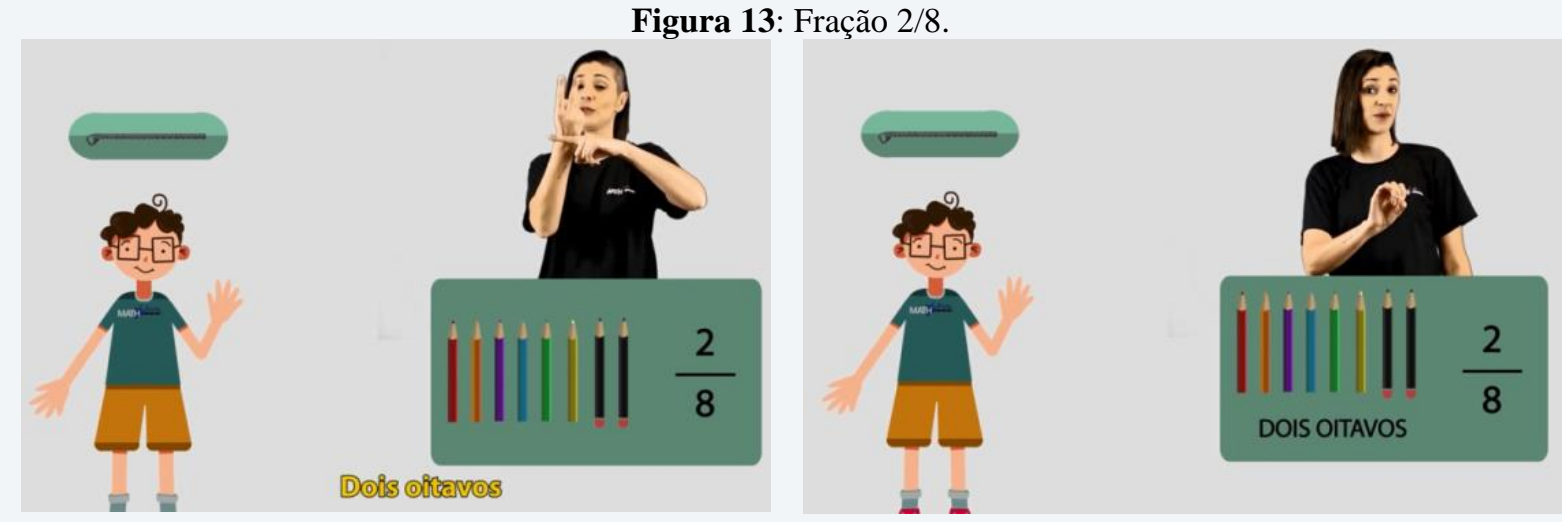

Fonte: Arquivo MathLibras, 2018.

Neste momento, caso o professor esteja utilizando o vídeo em sala de aula, pode fazer outros questionamentos: qual a fração que representa os lápis coloridos em relação ao total? Qual o total de lápis no seu estojo? Quantos são de escrever? Qual a fração que representa isto?

No segundo exemplo do vídeo a proposta inicial era separar os lápis das cores primárias, amarelo, azul e vermelho. Porém, ao discutir com a equipe achou-se que para crianças pequenas o conceito de cores primárias não faria sentido. Então, ao olhar as cores disponíveis no estojo do Levi optou pelas cores da bandeira do RS.

Figura 14: Cores da bandeira do RS.

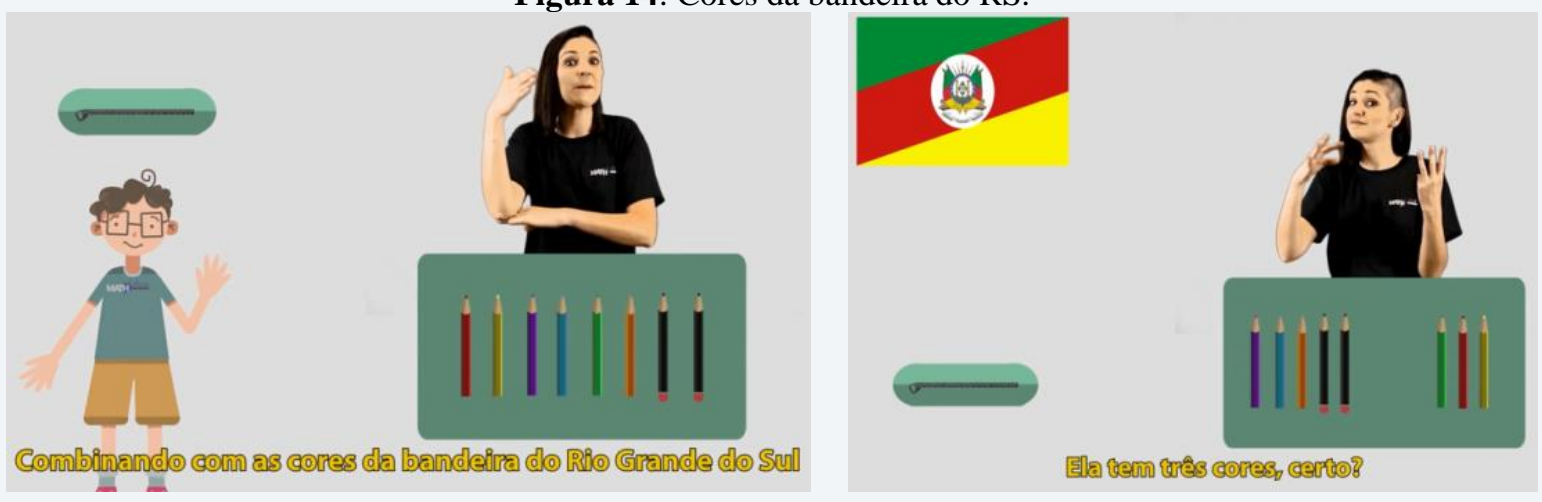

Fonte: Arquivo MathLibras, 2018. 
Ao aparecer a bandeira do RS a intérprete identifica as três cores: verde, vermelho e amarelo, e depois, encontra os lápis correspondentes. Primeiro faz o sinal da cor e na sequência o lápis ganha um destaque, para que a criança possa identificá-lo. Identificadas as três cores a intérprete propõe a separação dessas para um dos lados (Figura 14).

O processo para a construção da fração correspondente é similar: no denominador vai o total de lápis de Levi, oito, e no numerador o total de lápis separados conforme o critério das cores da bandeira do RS, três. A fração identificada é $\frac{3}{8}$.

Figura 15: Fração 3/8.
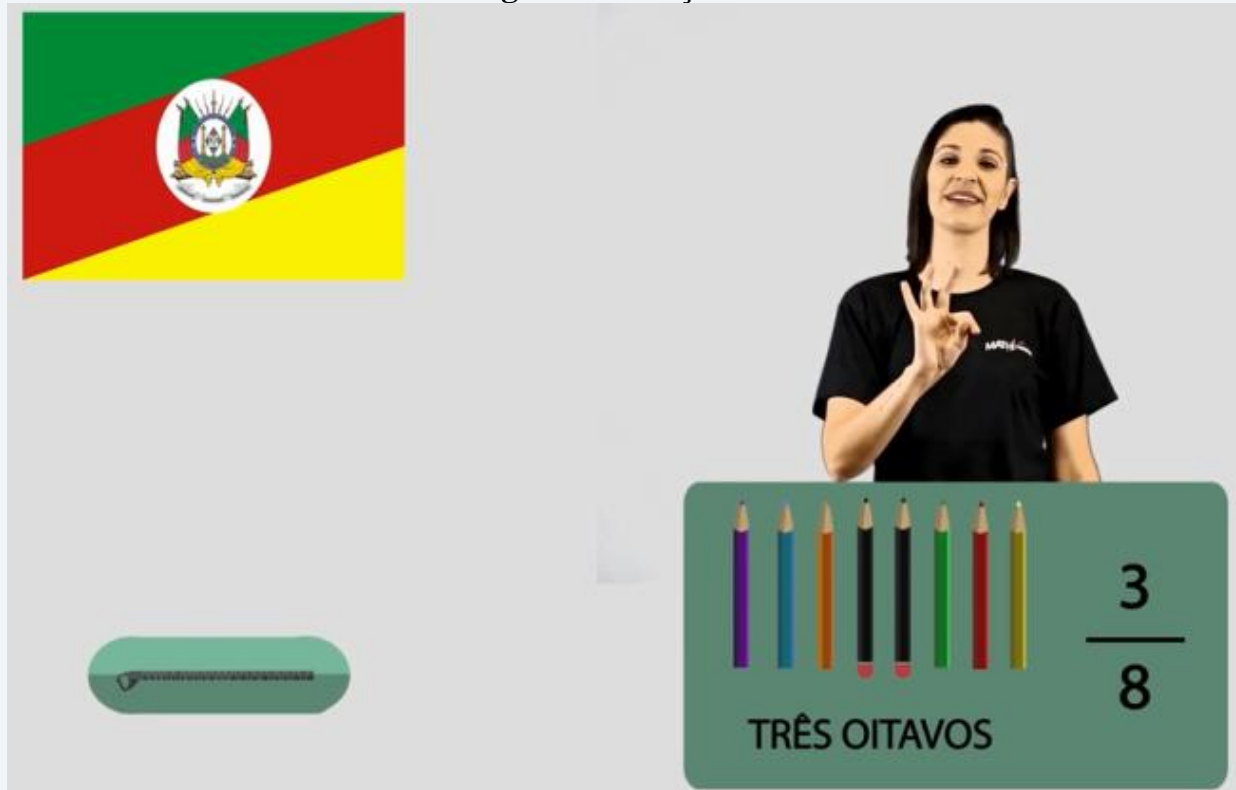

Fonte: Arquivo MathLibras, 2018.

Da Aula 1 para a Aula 2 algumas considerações: o material utilizado também foi de fácil acesso aos alunos: um estojo com lápis, sendo que podem reproduzir exatamente o material conforme o estojo de Levi, ou fazer uma adaptação para os lápis que possuem em seus próprios estojos.

Também, o número de elementos separados não foi somente um. O primeiro exemplo separou dois lápis pretos de um total de oito, e no segundo, separou três lápis de colorir, conforme as cores da bandeira do RS, representados pelas frações $\frac{2}{8} \mathrm{e} \frac{3}{8}$.

As aulas são independentes entre si, porém na segunda já não se tem uma fração com o numerador um, avançando no conteúdo e trazendo outros elementos para o diálogo, como a bandeira do estado. 


\section{Algumas considerações}

Os resultados de avaliação da fase de instalação do MathLibras bem como a produção dos primeiros vídeos possibilitaram várias inferências: i) a simples tradução linguística dos roteiros dos vídeos não dá conta das questões culturais e pragmáticas da língua para a qual se quer a tradução, neste caso a Libras; ii) há a necessidade de produção das videoaulas de Matemática em Libras considerando a cultura e a identidade do aluno surdo; iii) a Pedagogia Visual requer uma imersão cultural no mundo surdo, nos modos que os sujeitos surdos interagem e compreendem o mundo, a partir de sua experiência visual; iv) a Libras, nos vídeos, não pode ser um "recurso de inclusão", mas sim, a protagonista no ensino de conteúdos matemáticos; v) em relação à inferência (iv), os roteiros podem ser, num primeiro momento, pensados pela área da Educação Matemática com seu registro em Português, mas, precisam ser retextualizados em Libras para depois serem traduzidos para o Português, a fim de produzir a legendagem e vi) A videoaula como uma tecnologia assistiva oportuniza uma novo recurso de ensino ao aluno surdo, permitindo-o acessar o material tantas vezes quanto desejar.

A tecnologia de produção de audiovisuais deu condições para que os vídeos do MathLibras propiciem, acredita-se, o protagonismo da Libras como língua de instrução, na perspectiva da Pedagogia Visual e Textualidade Diferida. É importante ressaltar, ainda, a importância do trabalho em uma equipe multidisciplinar e da comunicação contínua entre os diferentes grupos que constituem o projeto. Sem a disposição dos diferentes participantes estudarem Libras e sem a comunicação que emergia nos momentos coletivos, o projeto não teria o resultado que teve.

\section{Agradecimento}

Ao Conselho Nacional de Desenvolvimento Científico e Tecnológico - CNPq.

\section{REFERÊNCIAS}

ABREU, S. M. Convencionamento de Sinais em Libras para o Ensino de Matemática na Educação Básica. 2016. 62 f. Dissertação (Mestrado em Ciências e Tecnologias na Educação) - Instituto Federal Sul-Rio-Grandense, Campus Pelotas - Visconde da Graça, Pelotas-RS, 2016.

ARAUJO,E. G. Ensino de Matemática em Libras: reflexões sobre minha experiência numa escola especializada. 2015. 244 f. Tese (Doutorado em Educação Matemática) - 
Coordenadoria de Pós-graduação, Universidade Anhanguera de São Paulo, São Paulo, 2015. Disponível em: <http://www.matematicainclusiva.net.br/pdf/TESEENIOFINAL.pdf>. Acesso em: 08 set. 2019.

BORBA M.de C.; SILVA, R. S. R. da; GADANIDIS, G. Fases das tecnologias digitais em Educação Matemática: sala de aula e internet em movimento. 2. ed. 2 reimp. Belo Horizonte: Autêntica, 2018.

BORGES, F. A. A educação inclusiva para surdos: uma análise do saber matemático intermediado pelo Intérprete de Libras. 2013. 259 f. Tese (Doutorado em Educação para a Ciência e a Matemática) - Programa de Pós-graduação em Educação para a Ciência e a Matemática, Universidade Estadual de Maringá, Maringá-PR, 2013.

BRASIL. Lei $\mathbf{N}^{\mathbf{0}}$ 10.436, de 24 de Abril de 2002. Disponível em: $<$ http://www.planalto.gov.br/ccivil_03/LEIS/2002/L10436.htm>. Acesso em: 03 jan. 2018.

BRASIL. Decreto No 5.626, de 22 de Dezembro de 2005. Disponível em: $<$ http://www.planalto.gov.br/ccivil_03/_ato2004-2006/2005/decreto/d5626.htm>. Acesso em: 08 jan. 2018.

BRASIL. Base Nacional Comum Curricular. Ministério da Educação. 2018. Disponível em:

$<$ http://basenacionalcomum.mec.gov.br/images/BNCC_EI_EF_110518_versaofinal_site.pdf. Acesso em: 05 set. 2019.

CAMPELLO, A. R. S. Pedagogia visual/sinal na educação dos surdos. In: QUADROS R. M., PERLIN, G. (Orgs). Estudos Surdos II. Petrópolis, RJ: Arara Azul, 2007.

CAMPELLO, A. R. S. Aspectos da visualidade na educação de surdos. 2008. 245 f. Tese (Doutorado em Educação) - Programa de Pós-Graduação em Educação, Universidade Federal de Santa Catarina, Florianópolis-SC, 2008.

DAMIANI, M. F.; ROCHEFORT, R. S.; CASTRO, R. F.; DARIZ, M. R.; PINHEIRO, S. S. Discutindo pesquisas do tipo intervenção pedagógica. Cadernos de Educação. Pelotas, FaE/PPGE/UFPel, v. 45. p. 57-67, maio/agosto 2013.

LACERDA, C. B. F. de; SANTOS, L. F. dos; CAETANO, J. F. Estratégias metodológicas para o ensino de alunos surdos. In: LACERDA, C. B. F. de; SANTOS, L. F. dos (Org.)

Tenho um aluno surdo, e agora?: Introdução à LIBRAS e educação de surdos. São Carlos: EdUFCSCar, 2014. Cap. 11, p.185-200.

LEBEDEFF, T. B. Aprendendo a ler "com outros olhos": relatos de oficinas de letramento visual com professores surdos. Cadernos de Educação. Pelotas, FaE/PPGE/UFPel, v. 36. p. 175-195, maio/agosto 2010.

LEBEDEFF, T. B. O povo do olho: uma discussão sobre a experiência visual e surdez. In:

LEBEDEFF, T. B. (Org.). Letramento visual e surdez. Rio de Janeiro: WAK Editora, 2017, p. 226-251. 
LORENZATO, S. Educação infantil e percepção matemática. Campinas, SP: Autores Associados, 2006.

MARTINS, V. S.; SANTOS, P. O desempenho escolar em matemática: um estudo sobre as dificuldades encontradas por estudantes no ensino

fundamental.InterdisciplinaryScientificJournal. v. 5, n. 5, Dec, 2018.

MOURA, M. C. de. Surdez e Linguagem. In: LACERDA, C. B. F. de; SANTOS, L. F. dos (Org.) Tenho um aluno surdo, e agora?: Introdução à LIBRAS e educação de surdos. São Carlos: EdUFSCar, 2014. Cap. 1, p.13-26.

MOURA, A. Q. Educação matemática e crianças surdas: explorando possibilidades em um cenário para investigação. 2015. Dissertação (Mestrado em Educação Matemática) Programa de Pós-graduação em Educação Matemática, Instituto de Geociências e Ciências Exatas, Universidade Estadual Paulista "Júlio de Mesquita Filho", campus de Rio Claro, Rio Claro-SP, 2015.

MUNIZ, C. A. As crianças que calculavam: o ser matemático como sujeito produtor de sentidos subjetivos na aprendizagem. In: XII Encontro Nacional de Educação Matemática (ENEM). São Paulo, 2016. Disponível em:

<http://www.sbembrasil.org.br/enem2016/anais/pdf/5317_2410_ID.pdf >. Acesso em 08 set. 2019.

NOGUEIRA, C. M. I. (Org). Surdez, inclusão e matemática. Curitiba: CRV, 2013.

NUNES, T. et al. Promovendo o Sucesso das Crianças Surdas em Matemática: Uma Intervenção Precoce. In: Cuadernos de Investigación y FormaciónenEducación Matemática. 2013. Año 8. Número 11. pp 263-275. Costa Rica. Disponível em: <http://revistas.ucr.ac.cr/index.php/cifem/article/view/14731/13976>. Acesso em: 10 out. 2016.

PELUSO, L. Traducción entre español escrito y lengua de señasuruguayavideograbada:unnuevodesafío. Cadernos de Tradução, Florianópolis, v. 35, n. especial 2, p. 479-504, jul-dez, 2015.

QUADROS, R. M. Educação de Surdos: a aquisição da linguagem. Porto Alegre: Artes Médicas, 1997.

RAMOS, L. F. Conversas sobre números, ações e operações: uma proposta criativa para o ensino da matemática nos primeiros anos. São Paulo: Ática, 2009.

SILVA, M. C. A. da. A escrita numérica por crianças surdas bilíngues. 2008. 266 f. Dissertação (Mestrado em Educação para a Ciência e o Ensino de Matemática) - Programa de Pós-Graduação em Educação para a Ciência e o Ensino de Matemática, Universidade Estadual de Maringá, Maringá-PR, 2008.

SILVA, M. C. A. da. Os surdos e as notações numéricas. Maringá, PR: Eduem, 2010. 
SILVA, A. A. da; CHAGAS, F. A. O.; PIMENTA, A. C.; FERREIRA, R. A. Ensino de frações no ensino fundamental: contribuição da tecnologia de comunicação e informação para uma pedagogia visual. In: Anais do $3^{\circ}$ ELPED e do $4^{\circ}$ ELICPIBID. Ciclo Revista: experiências em formação no IF Goiano, v. 3, n. 1, 2018. Disponível em: <https://www.ifgoiano.edu.br/periodicos/index.php/ciclo/article/view/846/676>. Acesso em: 25 out. 2018.

SKLIAR, C. Os estudos surdos na educação: problematizando a normalidade. In: SKLIAR, C. (Org.). A surdez: um olhar sobre as diferenças. 8. ed. Porto Alegre: Mediação, 2016. Cap. 1. p. 7-32.

SMOLE, K. S.; DINIZ, M. I. (Org). Materiais manipulativos para o ensino de frações e números decimais. Porto Alegre: Penso, 2016.

STROBEL, K. As imagens do outro sobre a cultura surda. 2. ed. Florianópolis: Ed. da UFSC, 2009.

VIANA, F. R.; BARRETO, M. C. O ensino de matemática para alunos com surdez: desafios docentes, aprendizagens discentes. Curitiba: CRV, 2014.

\section{SOBRE AS AUTORAS:}

\section{Thaís Philipsen Grützmann}

Doutora em Educação, UFPel; Universidade Federal de Pelotas-Brasil; Programa de PósGraduação em Educação Matemática; Grupo de Estudos sobre Educação Matemática com ênfase nos Anos Iniciais (GEEMAI). E-mail: thaisclmd2@ gmail.com

(iD http://orcid.org/0000-0001-6015-1546

\section{Rozane da Silveira Alves}

Doutora em Educação, UFPel; Universidade Federal de Pelotas-Brasil; Programa de PósGraduação em Educação Matemática; Grupo de Pesquisa Comunicação, Cultura, Tecnologias e Modos de Subjetivação. E-mail: rsalvex@gmail.com

(iD) http://orcid.org/0000-0001-9409-3495

\section{Tatiana BolivarLebedeff}

Doutora em Psicologia do Desenvolvimento; Universidade Federal do Rio Grande do sul (UFRGS); Universidade Federal de Pelotas-Brasil; Programa de Pós-Graduação em Letras; Grupo Interinstitucional de Pesquisa em Educação de Surdos (GIPES). E-mail: tblebedeff@gmail.com

(iD http://orcid.org/0000-0003-0586-349X

Recebido em: 22 de outubro de 2019 Aprovado em: 23 de novembro de 2019

Publicado em: 01 de janeiro de 2020 